\title{
Role of MRI to Predict Injury Patterns of the Medial Patellofemoral Ligament in Patellofemoral Instability
}

\author{
Nam QD Vo*1 and Toan N Nguyen ${ }^{2}$ \\ ${ }^{1}$ Hospital for Traumatology and Orthopaedics, Vietnam \\ ${ }^{2}$ Vietnam Military Medical University, Vietnam
}

Received: February 13, 2017; Published: February 21, 2018

*Corresponding author: Nam QD Vo, Hospital for Traumatology and Orthopaedics, HCM City, Vietnam, Tel: 84 903729772; Email: namvqd@hotmail.com

\begin{abstract}
Abbreviations: M: Mature; I: Immature; IF: Isolated Femoral Attachment; IP: Isolated Patellar Insertion; MID: Isolated Mid-Substance; COM: Combined MPFL Injuries; C: Complete Tear; P: Partial Tear
\end{abstract}

\section{Introduction}

Patello femoral instability (PFI) is a debilitating injury for the patient and a challenging problem for the surgeon. The incidence of PFI ranges from 5.8 to 77.8 per 100,000 and recurrence rates of nonoperatively treated dislocations range from $15 \%$ to $50 \%$ [1]. In children and adolescents, the recent studies showed the incident of PFI of 43 per 100,000 [2] and the recurrent rates between $30 \%$ and 38\% [2,3]. The medial patella femoral ligament (MPFL) is the primary soft-tissue restraint to lateral patellar translation [4]. The MPFL has a "sail-like" appearance with two functional portions: inferior straight bundle and superior oblique bundle. The MPFL originates from the medial femoral condoyle just proximal to the femoral attachment of the medial collateral ligament and distal to the adductor tubercle. It inserts on the super medial border of the patella. In children and adolescents with open phases, the femoral insertion is located slightly distal ( 4 to $5 \mathrm{~mm}$ ) to the medial femoral physics [5]. During 0 to 30 degrees of knee flexion, the MPFL contributes more than $60 \%$ of the medial stability of the patella and isolated insufficiency leads to increased lateralization or dislocation [6].

In cases of first-time acute lateral patellar dislocation, injury to the MPFL is described as the essential lesion, occurring in almost $100 \%$ of cases [7]. Repair, reefing, and advancement of the MPFL

Table 1: MRI-based studies of MPFL injury patterns. and medial retinacular structures can be performed as an isolated procedure or in conjunction with distal realignment procedures for patients with patellar instability. Understanding and appreciating MPFL injury patterns ultimately determines the success or failure of these procedures. Unfortunately, the location and pattern of MPFL injury cannot be consistently predicted [2]. Although early surgical dissections described femoral-sided injuries as the most common injury site, the recent studies using magnetic resonance imaging (MRI) have described a more even distribution of MPFL injury patterns, which include isolated patellar insertion ruptures, isolated femoral attachment ruptures, isolated mid-substance ruptures, and combined MPFL injuries [8].

This review focuses on the MRI-based studies of MPFL injury patterns, and related factors as age, injury severity and acute or recurrent PFI. These studies are shown in the (Table 1). Although most of these 9 studies (7 studies) are of primary PFI, prevalence of MRI-defined MPFL injuries ranges from $44.4 \%$ to $100 \%$; and injury prediction in immature patient is much lower than in mature patient [3,9] and Wilson [9] stated that MPFL did not always tear in immature PFI. Some authors recommended some solutions that complement to investigate MPFL injuries as arthroscopic surgery [6], HR-MRI with microscopy coin [10]. In acute MPFL injuries, the complete tear is a bit more popular than the partial tear $[11,12]$.

\begin{tabular}{|c|c|c|c|c|c|}
\hline & Kind of PFI & No of cases & Age & \% injuries detected & Position of MPFL tear \\
\hline Dragoo [1] & recurrent & 24 & M & $100 \%$ & 16 IF or IP, 8 both or inadequately visualized \\
\hline Seeley [3] & primary & 111 & I & $87(78.4 \%)$ & IP 31\%, IF 14\%, COM 33\% \\
\hline Kepler [5] & primary & 43 & I & $94 \%$ & IP 61\%, IF 12\%, COM 21\% \\
\hline Tompkins [9] & primary & 157 & 107 M, 50 I & $87 \%$ & C 44\%, P 43\%; IF 10\%, IP 17\%,MID 0\%, COM 61\% \\
\hline
\end{tabular}




\begin{tabular}{|c|c|c|c|c|c|}
\hline Askenberger [10] & primary & 74 & I & $73(99 \%)$ & IP 60\%, COM 35\%,IF 4\% \\
\hline Zhang [11] & primary & 121 & M & $119(98 \%)$ & IF 39.7\%, IP 29.7\%, MID 4.1\%, COM 24.8\% \\
\hline Zheng [12] & primary & 127 & I & $123(97 \%)$ & C 54.3\%, P 42.5\%; IP 37\%, IF 32.3\%, MID 3.1\%, COM \\
\hline Wilson [13] & primary & 36 & I & $16(44.4 \%)$ & IP 22.2\%, IF 22.2\%, MID \& COM 0\% \\
\hline Iwama [14] & recurrent & 15 & M & $12(87 \%)$ & NA \\
\hline
\end{tabular}

For detecting the location of MPFL injury, these studies in mature patients did not show what is the most among isolated patellar insertion ruptures, isolated femoral attachment ruptures, isolated mid-substance ruptures, and combined injuries; except the isolated mid-substance rupture was very rare $0-4 \%[1,11,13]$. However, many studies proved the dominance of isolated patellar insertion ruptures in immature patients, and the combined MPFL injuries were more popular than the isolated femoral attachment ruptures, and the isolated mid-substance rupture was also very rare in immature patients $0-3 \%[3,5,9,11,12,14]$. On the other hand, the complete MPFL tear was more often concomitant with osteochondral lesions of the lateral femoral condyle than the partial MPFL tear; the isolated patellar insertion ruptures and the combined MPFL injuries were more easily concomitant with osteochondral lesions of the lateral femoral condyle than the isolated femoral attachment ruptures. These results were from a study in adults [13] and a study in children and adolescents [12].

\section{Conclusion}

In conclusion, the location and pattern of MPFL injury were not consistently predicted on MRI and many studies proved the dominance of isolated patellar insertion ruptures in immature patients. Moreover, there is still the lack of MRI-based studies of MPFL injury for recurrent PFI.

\section{References}

1. Dragoo JL, Nguyen M, Gatewood CT, Taunton JD, Young S (2017) Medial Patellofemoral Ligament Repair Versus Reconstruction for Recurrent Patellar Instability: Two-Year Results of an Algorithm-Based Approach. Orthop J Sports Med 5(3): 2325967116689465.

2. Lewallen LW, McIntosh AL, Dahm DL (2013) Predictors of recurrent instability after acute patellofemoral dislocation in pediatric and adolescent patients. Am J Sports Med 41(3): 575-581.

3. Seeley M, Bowman KF, Walsh C, Sabb BJ, Vanderhave KL (2012) Magnetic resonance imaging of acute patellar dislocation in children: patterns ofinjury and risk factors for recurrence. J Pediatr Orthop 32(2):145-155.
4. Hautamaa PV, Fithian DC, Kaufman KR, Daniel DM, Pohlmeyer AM (1998) Medial soft tissue restraints in lateral patellar instability and repair. Clin Orthop Relat Res (349): 174-182.

5. Kepler CK, Bogner EA, Hammoud S, Malcolmson G, Potter HG, et al (2011) Zone of injury of the medial patellofemoral ligament after acute patellar dislocation in children and adolescents. Am J Sports Med 39(7): 1444-1449.

6. Desio SM, Burks RT, Bachus KN (1998) Soft tissue restraints to lateral patellar translation in the human knee. Am J Sports Med 26(1): 59-65.

7. Duchman KR, Bollier MJ (2017) The Role of Medial Patellofemoral Ligament Repair and Imbrication. Am J Orthop (Belle Mead NJ) 46(2): 87-91.

8. Petri M, Von Falck C, Broese M, Liodakis E, Balcarek P, et al. (2013) Influence of rupture patterns of the medial patellofemoral ligament (MPFL) on the outcome after operative treatment of traumatic patellar dislocation. Knee Surg Sports Traumatol Arthrosc 21(3): 683-689.

9. Wilson A, Afarin A, Shaw C, Shirley E, Pierce J, et al. (2013) Magnetic Resonance Imaging Findings After Acute Patellar Dislocation in Children. Orthop J Sports Med 1(6): 2325967113512460.

10. Iwama Y, Fujii M, Shibanuma H, Muratsu H, Kurosaka M, et al. (2006) High-resolution MRI using a microscopy coil for the diagnosis of recurrentlateral patellar dislocation. Radiat Med 24(5): 327-334.

11. Tompkins MA, Rohr SR, Agel J, Arendt EA (2017) Anatomic patellar instability risk factors in primary lateral patellardislocations do not predict injury patterns: an MRI-based study. Knee Surg Sports Traumatol Arthrosc.

12. Zheng L, Shi H, Feng Y, Sun BS, Ding HY, et al. (2015) Injury patterns of medial patellofemoral ligament and correlation analysis witharticular cartilage lesions of the lateral femoral condyle after acute lateralpatellar dislocation in children and adolescents: An MRI evaluation. Injury 46(6): 1137-1144.

13. Zhang GY, Zheng L, Feng Y, Shi H, Liu W, et al. (2015) Injury patterns of medial patellofemoral ligament and correlation analysis with articular cartilage lesions of the lateral femoral condyle after acute lateralpatellar dislocation in adults: An MRI evaluation. Injury 46(12): 2413-2421.

14. Askenberger M, Arendt EA, Ekström W, Voss U, Finnbogason T, et al. (2016) Medial Patellofemoral Ligament Injuries in Children With FirstTime LateralPatellar Dislocations: A Magnetic Resonance Imaging and Arthroscopic Study. Am J Sports Med. 44(1): 152-158.

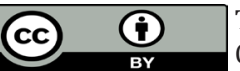

This work is licensed under Creative Commons Attribution 4.0 License

Submission Link: http://biomedres.us/submit-manuscript.php

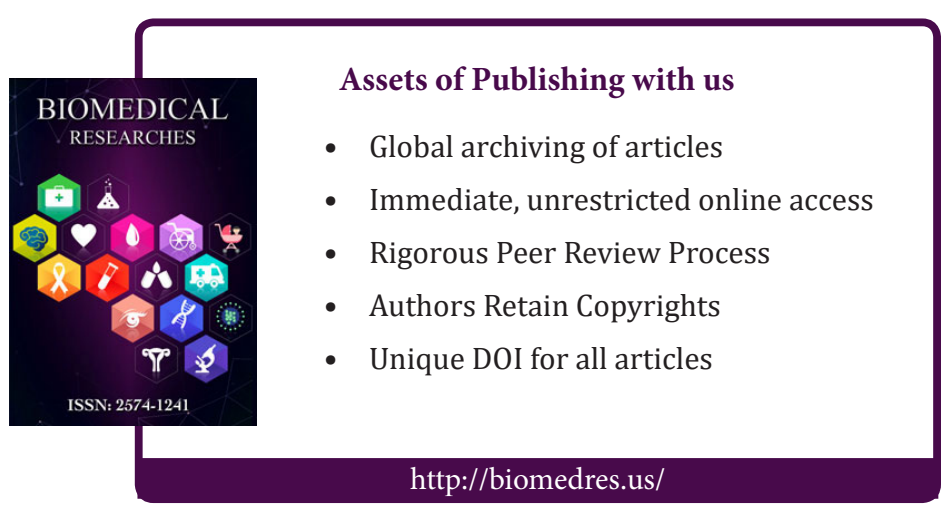

